\title{
The predictive prognostic factors and risk factors of lymph node metastasis in patients with early gastric cancer
}

\section{hongliang zu}

Tongji University school of Medicine

huiling Wang

Tongji University school of Medicine

\section{yan MA}

Tumor Hospital of Harbin Medical University

yingwei xue ( $\nabla$ yingweixue1@126.com )

Harbin Medical University https://orcid.org/0000-0002-6407-2703

Research article

Keywords: Early gastric cancer, Preoperative Hb level, Lymph node metastasis

Posted Date: August 14th, 2019

DOl: https://doi.org/10.21203/rs.2.12784/v1

License: (c) (i) This work is licensed under a Creative Commons Attribution 4.0 International License. Read Full License 


\section{Abstract}

Background: Determining the prognosis of early gastric cancer (EGC) is very important for the selection of preoperative treatment strategies. The purpose of this paper was to investigate the clinicopathological features and prognostic factors in EGC and the related risk factors of lymph node metastasis (LNM). Methods: From March 2007 through December 2010, 1004 patients who underwent gastrectomy at Harbin Medical University were retrospectively identified; 120 patients were diagnosed with EGC. The clinicopathological features and prognostic factors were analysed by univariate and multivariate analyses. Multivariate logistic regression analysis was used to discern risk factors for LNM in EGC. Results: The incidence of EGC was $11.96 \%$. A univariate analysis showed that age, preoperative haemoglobin $(\mathrm{Hb})$ level, prealbumin level, tumour size and LNM were significant prognostic factors. A multivariate analysis showed that the preoperative $\mathrm{Hb}$ level and LNM were independent prognostic factors. A multivariate logistic regression analysis revealed that age, Ca-199 level and macroscopic tumour type were independent risk factors for LNM in EGC. Conclusions: Preoperative $\mathrm{Hb}$ level and LNM were both independent prognostic factors for EGC. These factors may help surgeons implement appropriate treatment strategies during the perioperative period.

\section{Background}

Approximately 989,000 people worldwide are diagnosed annually with gastric cancer (GC), and approximately 738,000 of them die of the disease [1]. GC remains the second leading cause of cancerrelated death worldwide and is the most common cancer in Eastern Asia [2]. Over 70\% of cases occur in developing countries, mainly in China [3]. Of all patients, most are at an advanced stage at the time of diagnosis, and the incidence of early gastric cancer (EGC) is nearly $10 \%$ [4]. At present, the treatment of EGC primarily includes endoscopic mucosal resection (EMR) [5], endoscopic submucosal dissection (ESD) [6] and open or laparoscopic radical gastrectomy $[7,8,9]$. Radical gastrectomy is usually used to treat patients with EGC; although this treatment can achieve adequate oncological resection margins and lymphadenectomy, it is still associated with some postsurgical complications [10]. On the other hand, although endoscopic treatment has been widely used in the treatment of EGC [11,12], higher recurrence rates and metachronous cancer are still concerns [13]. This study retrospectively analysed the clinicopathological characteristics and prognosis of EGC patients and related risk factors of lymph node metastasis (LNM) and provided information for the choice of optimal therapies for EGC.

\section{Patients And Methods}

Between 2007 and 2009, 1004 patients with histologically proven primary gastric adenocarcinoma underwent gastrectomy at the Department of Surgical Gastroenterology, Affiliated Tumour Hospital of Harbin Medical University, Harbin, China. Among the patients, 120 patients were diagnosed with EGC. According to the WHO classification $[14,15]$, the diagnosis of EGC refers to a tumour confined to the mucosa or the submucosa, irrespective of the presence of regional LNMs. None of these patients received neoadjuvant chemotherapy or radiotherapy before surgery. This retrospective study was approved by the 
Ethics Committee of Harbin Medical University, and all patients provided informed consent before enrolment in the study. The stomach was divided into three portions, which were defined by subdividing the lesser and greater curvatures into three equal lengths, as described in the Japanese Classification of Gastric Cancer [16]: proximal, middle and distal. The following clinicopathological parameters were collected: sex (male or female); age (mean, SD); preoperative haemoglobin (Hb) (mean, SD); prealbumin (Pre-ALB) (mean, SD); tumour size (mean, SD); carcinoembryonic antigen (CEA) level (mean, SD); Ca-199 level (mean, SD); macroscopic tumour type (elevated, flat, depressed, mixed, $X$ ) [17]; degree of differentiation (well differentiated, moderately differentiated, poorly differentiated, mucinous carcinoma or signet ring cell carcinoma; if two or more histological types were present, the histological type was defined by the predominant type in the tumour); depth of tumour invasion (T1a: tumour has invaded the mucosal layer; T1b: tumour has invaded the submucosal layer); and the 7th American Joint Committee on Cancer (AJCC) lymph node status (N0, N1, N2, N3a, or N3b, as shown Table 1). Moreover, we evaluated the clinicopathologic features in patients with early gastric carcinoma with and without LNM.

\section{Follow-up and statistical analysis}

Patient follow-up lasted until death or the cut-off date of March 30, 2016. For patients who survived, data were censored at the date of last contact. Only cases in which patients died of GC were classified as tumour-related deaths. Continuous variables were expressed as the mean \pm standard deviations. Chisquared and Fisher exact tests were used to analyse the associations between categorical variables, and the t-test was used to compare continuous variables. Survival data were estimated using the Kaplan-

Meier method; the log-rank test was used to analyse the significant prognostic factors in EGC and to compare the different survival rates of patients with or without LNM. A multivariate analysis of prognostic factors related to overall survival was performed using a Cox proportional hazards model. A multivariate logistic regression model was used to analyse the multivariate predictors of LNM. The criterion for statistical significance was $p<0.05$. All data analyses were performed using SPSS for Windows, Version 22.0 software (SPSS Inc., Chicago, IL, USA).

\section{Results}

\section{Clinicopathological features}

Table 1 describes the clinicopathological features and prognostic single-factor analysis of the EGC cases. In these patients, 73 were men and 47 were women, and the male to female sex ratio was approximately 1.55. The average age was $54.74 \pm 11.68$ years (range, 28 to 78 years). The average preoperative $\mathrm{Hb}$ level was $135.09 \pm 22.76 \mathrm{~g} / \mathrm{l}$, and the average prealbumin level was $280.34 \pm 67.36 \mathrm{mg} / \mathrm{dl}$. The mean tumour size was $2.81 \pm 2.11 \mathrm{~cm}$. The average Ca-199 level was $11.94 \pm 16.38 \mathrm{U} / \mathrm{ml}$. Most patients were diagnosed with distal tumours (78.3\%). Macroscopically, the flat type tumour was the most common (38.33\%), followed by the depressed type (33.33\%), elevated type (17.5\%), and mixed type (5\%). According to the differentiation, 12 (10\%) were well-differentiated adenocarcinomas, $55(45.8 \%)$ were moderately differentiated adenocarcinomas, 44 (36.7\%) were poorly differentiated adenocarcinomas, and 7 (5.8\%) 
were signet ring cell carcinomas. LNM was detected in 19 patients; the incidence of node-positive EGC was $11.96 \%$ (19/120). Twenty-eight patients $(23.3 \%)$ had mucosal cancers and 92 patients $(76.7 \%)$ had submucosal cancers. The incidence of node-positive EGC was $17.8 \%$ in patients with mucosal tumours and $15.2 \%$ in those with submucosal tumours.

The univariate analysis revealed a close relationship between age and $\mathrm{Ca}-199$ level and LNMs $(\mathrm{p}=$ $0.014 ; p=0.043$ ). No significant correlation was observed among LNM and sex, $\mathrm{Hb}$, prealbumin, CEA, tumour size, tumour location, macroscopic type, differentiation and T stage $(p=0.451 ; p=0.095 ; p=$ $0.864 ; p=0.393 ; p=0.35 ; p=0.671 ; p=0.959 ; p=0.057 ; p=0.77$, respectively) (Table 3). A multivariate logistic regression analysis for variables associated with lymph node metastasis in EGC showed that age, Ca-199 level and macroscopic tumour type were independent prognostic factors (Table 4).

\section{Univariate and multivariate survival analyses}

A univariate survival analysis showed that age, preoperative $\mathrm{Hb}$ level, prealbumin level, tumour size and $\mathrm{N}$ stage were significant prognostic factors in EGC (as shown in Table 1). The Kaplan-Meier survival curve indicated that more LNMs were predictive of a worse prognosis compared with fewer LNMs in EGC (as shown in Fig. 1). A multivariate analysis showed that the preoperative $\mathrm{Hb}$ level and LNM were independent prognostic factors (as shown in Table 2).

\section{Discussion}

The incidence of EGC was $11.96 \%$ in our 1004 patients, which is similar to that in another study in China [18]. In the western hemisphere, EGC accounts for $4-16 \%$ of all gastric carcinoma cases [19]. In South Korea, the proportion of EGC accounts for $47.4 \%$ of all diagnosed GCs in 2004 [20], while in Japan, the proportion of EGC accounts for approximately $30-50 \%$ of all GCs [21]. The differences in incidence may be related to screening strategies and various economic and health levels in different countries.

In our study, the LNM rate in EGC was 15.8\%. Shen L et al [18] reported that LNM was observed in $12.20 \%$ of EGC patients. In another study [22], LNM was reported in $19.7 \%$ of EGC cases. The reported rates range from $5.7-20 \%$ of patients [23-28]. In our study, the node-positive rate of patients with EGC was $17.8 \%$ in those with tumours in the mucosal layer and $15.2 \%$ in those with tumours in the submucosal layer. As previously reported [28-29], once the tumour has invaded the submucosal layer, the rate of LNM increases significantly. However, we did not obtain the same result.

According to previous reports, anaemia is closely correlated with worse outcomes in cancer patients. For example, some studies have shown that anaemic patients with laryngeal [30], cervical [31], ovarian [32] and lung cancers exhibit worse survival $[33,34]$. A Korean study has shown that pretreatment anaemia is associated with poorer survival in patients with stage I and II GC [35]. Xuechao Liu et al found that preoperative anaemia, even mild anaemia, was an important predictor of postoperative survival of patients with TNM III GC [36]. Our study showed that the preoperative Hb level was an independent 
prognostic factor in EGC. This is a unique finding compared with the findings in previous reports. The $\mathrm{Hb}$ level may affect the prognosis of early-stage GC. These results may provide information used in the treatment of EGC. In the future, we will study the exact mechanism by which the preoperative $\mathrm{Hb}$ level influences EGC.

Many studies have evaluated LNM in EGC and have confirmed that LNM is the most crucial prognostic factor for EGC [37-40]. We also obtained this result. LNM and preoperative $\mathrm{Hb}$ level were independent prognostic factors in EGC. Fig. 1 shows that the prognosis of EGC patients with different $\mathrm{N}$ stages was significantly different $(p=0.000)$. Patients who were lymph node-positive were younger and had higher $\mathrm{Ca}-199$ values than those who were lymph node-negative. A multivariate logistic analysis for variables associated with LNM in EGC showed that age, $\mathrm{Ca}-199$ and macroscopic tumour type were independent prognostic factors. In a study of 376 patients with EGC who underwent gastrectomy, Lim et al [41] found that macroscopic tumour type was related to LNM. Another publication [18] also revealed that macroscopic tumour type and other factors were independent risk factors for LNM. These studies suggest that macroscopic tumour type is important for predicting LNM in EGC. Moreover, Roviello et al [42] analysed 652 EGC patients with LNM and confirmed age $(p=0.012, R S=0.97)$ as an independent predictor of nodal involvement. Fukuhara [43] also showed that younger age (OR, 1.11; 95\% $\mathrm{Cl}, 1.01-1.12$; $p=0.046$ ) was a significant predictor of LNM. Thus, younger patients with EGC may have more LNMs than older patients.

Limitations of this study include an inability to obtain a specific cut-off value for the preoperative $\mathrm{Hb}$ for predictive prognosis. We anticipate larger databases for further validation in the future. Another limitation was that this study analysed data originating from a single centre. In the future, we expect to perform a multi-centre and large-scale collaborative study to further demonstrate the prognostic significance of the preoperative $\mathrm{Hb}$ level in EGC.

In conclusion, we found that the preoperative $\mathrm{Hb}$ level and LNM were independent prognostic factors in EGC. Age, Ca-199 level and macroscopic tumour type were independent prognostic factors of LNM in EGC. The preoperative $\mathrm{Hb}$ level and LNM may help surgeons make better treatment decisions in the perioperative period.

\section{Abbreviations}

EGC: early gastric cancer; LNM $ه$ lymph node metastasis; Ca-199: cancer antigen-199; CEA: carcinoembryonic antigen; SD: standard deviation $\varangle \mathrm{Hb}$ : haemoglobin $\triangle \mathrm{X}$ : unknow type $\mathbb{E} \mathrm{EMR}$ : endoscopic mucosal resection; ESD: endoscopic submucosal dissection; Pre-ALB: prealbumin

\section{Acknowledgements}

Acknowledgements

Not applicable. 


\section{Funding}

Not applicable.

\section{Availability of data and materials}

The datasets used and/or analyzed during the current study are available from the corresponding author on reasonable request.

\section{Authors'contributions}

Hongliang Zu: analysis and interpretation of data,Study conception and design

Huiling Wang: data collection,drafting of article

Yan Ma: critical revision,drafting of article

Yingwei Xue: Study conception and design, analysis and interpretation of data; critical revision

\section{Ethics approval and consent to participate}

This retrospective study was approved by the Ethics Committee of Harbin Medical University, and all patients provided informed consent before enrolment in the study.

\section{Consent for publication}

Not applicable.

\section{Competing interests}

The authors declare that they have no competing interests.

\section{Author details}




\section{${ }^{1}$ Department of Gastroenterologic Surgery, Shanghai Fourth People's Hospital affiliated to Tongji University School of Medicine}

\section{${ }^{2}$ Department of ICU, Shanghai Fourth People's Hospital affiliated to Tongji University School of Medicine}

\section{${ }^{3}$ Department of Gastroenterologic Surgery, Affiliated Tumor Hospital of Harbin Medical University}

\section{References}

1. Ferlay J, Shin HR, Bray F, Forman D, Mathers C, Parkin DM. Estimates of worldwide burden of cancer in 2008: GLOBOCAN 2008. Int J Cancer. 2010; 127:2893-917.

2. Bray F, Ren JS, Masuyer E, Ferlay J. Global estimates of cancer prevalence for 27 sites in the adult population in 2008. Int J Cancer. 2013; 132:1133-45.

3. Goetze OT, Al-Batran SE, Chevallay M, Mönig SP. Multimodal treatment in locally advanced gastric cancer. Updates Surg. 2018 Jun;70(2):173-179.

4. Song Z, Wu Y, Yang J, Yang D, Fang X. Progress in the treatment of advanced gastric cancer. Tumour Biol.2017 Jul;39(7):1010428317714626. doi: 10.1177/1010428317714626.

5. Assoc JGC (2011) Japanese gastric cancer treatment guidelines 2010 (ver. 3). Gastric Cancer 14:113-123.

6. Lee IS, Yook JH, Park YS, Kim KC, Oh ST, Kim BS. Suitability of endoscopic submucosal dissection for treatment of submucosal gastric cancers. Br J Surg.2013 Apr;100(5):668-73. doi: 10.1002/bjs.9051. Epub 2013 Jan 18.

7. Kitaoka H, Yoshikawa K, Hirota T, Itabashi M.. Surgical treatment of early gastric cancer. Jpn J Clin Oncol.1984 Jun;14(2):283-93.

8. Kitano S, Iso Y, Moriyama M, Sugimachi K.. Laparoscopy-assisted Billroth I gastrectomy[J]. Surg Laparosc Endosc.1994 Apr;4(2):146-8.

9. Lee JH, Han HS, Lee JH. A prospective randomized study comparing open vs laparoscopy-assisted distal gastrectomy in early gastric cancer: early results[J]. Surg Endosc, 2005, 19: 168-173.

10. Folli S, Morgagni P, Roviello F, De Manzoni G, Marrelli D, Saragoni L. Risk factors for lymph node metastases and their prognostic significance in early gastric cancer (EGC) for the Italian Research Group for Gastric Cancer (IRGGC). Jpn J Clin Oncol 2001; 31: 495-499.

11. Japanese Gastric Cancer Association. Japanese gastric cancer treatment guidelines 2010 (ver. 3). Gastric Cancer 2011;14:113-123.

12. Gotoda T. Endoscopic resection of early gastric cancer. Gastric Cancer 2007; 10: 1-11 
13. Pyo JH, Lee H, Min BH, Lee JH, Choi MG, Lee JH, et al. Long-term outcome of endoscopic resection vs. Surgery for early gastric cancer: a non-inferiority-matched cohort study. Am J Gastroenterol.2016 Feb;111(2):240-9. doi: 10.1038/ajg.2015.427. Epub 2016 Jan 19.

14. Ferlay J, Steliarova-Foucher E, Lortet-Tieulent J, Rosso S, Coebergh JW, Comber H. Cancer incidence and mortality patterns in Europe: estimates for 40 countries in 2012. Eur J Cancer. 2013; 49: 13741403.

15. Aaltonen L, Hamilton S. Pathology and Genetics of Tumours of the Digestive System. 2000.

16. Japanese Gastric Cancer Association. Japanese classification of gastric carcinoma. 2nd English ed. Gastric Cancer.1998 Dec;1(1):10-24.

17. Japanese Gastric Cancer Association. Japanese classification of gastric carcinoma: 3rd English edition. Gastric 2011 Jun;14(2):101-12. doi: 10.1007/s10120-011-0041-5.

18. Shen L1, Huang Y, Sun M, Xu H, Wei W, Wu W.. Clinicopathological features associated with lymph node metastasis in early gastric cancer: Analysis of a single-institution experience in China. Can $\mathrm{J}$ Gastroenterol.2009 May;23(5):353-6.

19. Borie F, Millat B, Fingerhut A, Hay JM, Fagniez PL, De Saxce B. Lymphatic involvement in early gastric cancer: prevalence and prognosis in France. Arch Surg.2000 Oct;135(10):1218-23.

20. Association TICotKGC. 2004 Nationwide Gastric Cancer Report in Korea. J Korean Gastric Cancer Assoc. 2007;7: 47-54.

21. Okabayashi T, Kobayashi M, Nishimori I, Sugimoto T, Namikawa T, Onishi S,. Clinicopathological features and medical management of early gastric cancer. Am J Surg.2008 Feb;195(2):229-32.

22. Bausys R, Bausys A, Vysniauskaite,Maneikis K, Klimas D, Luksta M. Risk factors for lymph node metastasis in early gastric cancer patients: Report from Eastern Europe country-LithuaniaBausys. BMC Surg. 2017 Nov 23;17(1):108. doi: 10.1186/s12893-017-0304-0.

23. Wu CY, Chen JT, Chen GH, Yeh HZ. Lymph node metastasis in early gastric cancer: a clinicopathological analysis.Hepatogastroenterology. Hepatogastroenterology.2002 SepOct;49(47):1465-8.

24. Mouri R, Yoshida S, Tanaka S, Oka S, Yoshihara M, Chayama K. Usefulness of endoscopic ultrasonography in determining the depth of invasion and indication for endoscopic treatment of early gastric cancer.J Clin Gastroenterol.2009 Apr;43(4):318-22. doi:

10.1097/MCG.0b013e3181775966.

25. Boku T, Nakane Y, Okusa T, Hirozane N, Imabayashi N, Hioki K, etal. Strategy for lymphadenectomy of gastric cancer. Surgery.1989 May;105(5):585-92.

26. Popiela T, Kulig J, Kolodziejczyk P, Sierzega M. Long-term results of surgery for early gastric cancer. Br J Surg. 2002;89:1035-42.

27. Seto Y, Shimoyama S, Kitayama J, Mafune K, Kaminishi M, Aikou T, et al. Lymph node metastasis and preoperative diagnosis of depth of invasion in early gastric cancer. Gastric Cancer. 2001;4(1):348. 
28. Ren G, Cai R, Zhang WJ,Ou JM, Jin YN, Li WH.. Prediction of risk factors for lymph node metastasis in early gastric cancer. World J Gastroenterol. 2013 May 28;19(20):3096-107.

29. Wang $Y$. The predictive factors for lymph node metastasis in early gastric cancer: A clinical study. Pak J Med Sci. 2015 Nov-Dec;31(6):1437-40.

30. Grant DG, Hussain A, Hurman D. Pre-treatment anaemia alters outcome in early squamous cell carcinoma of the larynx treated by radical radiotherapy. J Laryngol Otol. 1999;113:829-833.

31. Dunst J, Kuhnt T, Strauss HG, Krause U, Pelz T, Koelbl H, et al. Anemia in cervical cancers: Impact on survival, patterns of relapse, and association with hypoxia and angiogenesis. Int $\mathrm{J}$ Radiat Oncol Biol Phys.2003 Jul 1;56(3):778-87.

32. Munstedt K, Kovacic M, Zygmunt M, Von Georgi R.. Impact of hemoglobin levels before and during chemotherapy on survival of patients with ovarian cancer. Int J Oncol. 2003 Sep;23(3):837-43.

33. Wigren T, Oksanen H, Kellokumpu-Lehtinen P. A practicalprognostic index for inoperable non-smallcell lung cancer. J Cancer Res Clin Oncol 1997;123:259-266.

34. Yovino S1, Kwok Y, Krasna M, Bangalore M, Suntharalingam M. An association between preoperative anemia and decreased survival in early-stage non-smallcell lung cancer patients treated with surgery alone.Int J Radiat Oncol Biol Phys.2005 Aug 1;62(5):1438-43.

35. Shen JG, Cheong JH, Hyung WJ, Kim J, Choi SH, Noh SH. Pretreatment anemia is associated with poorer survival in patients with stage I and II gastric cancer.J Surg Oncol. 2005 Aug 1;91(2):126-30.

36. Liu X, Qiu H, Huang Y, Xu D, Li W, Li Y, etal. Impact of preoperative anemia on outcomes in patients undergoing curative resection for gastric cancer: a single-institution retrospective analysis of 2163 Chinese patients.Cancer Med. 2018 Feb;7(2):360-369.

37. Ye BD, Kim SG, Lee JY, Kim JS, Yang HK, Kim WH, et al. Predictive factors for lymph node metastasis and endoscopic treatment strategies for undifferentiated early gastric cancer.J Gastroenterol Hepatol.2008 Jan;23(1):46-50.doi: 10.1111/j.1440-1746.2006.04791.x.

38. Hirasawa T, Gotoda T, Miyata S, Kato Y, Shimoda T, Taniguchi H, et al. Incidence of lymph node metastasis and the feasibility of endoscopic resection for undifferentiated type early gastric cancer. Gastric Cancer.2009;12(3):148-52.

39. Chen R, He Q, Cui J, Bian S, Chen L. Lymph node metastasis in early gastric cancer.Chin Med J (Engl).2014;127(3):560-7.

40. Zhao BW, Chen YM, Jiang SS, Chen YB, Zhou ZW, Li YF. Lymph Node Metastasis, a Unique Independent Prognostic Factor in Early Gastric Cancer. PLoS One. $2015 \mathrm{Jul}$ 8;10(7):e0129531. doi: 10.1371/journal.pone.0129531. eCollection 2015.

41. Lim MS, Lee HW, Im H, Kim BS, Lee MY, Jeon JY, et al. Predictable factors for lymph node metastasis in early gastric cancer-analysis of single institutional experience. J Gastrointest Surg.2011 Oct;15(10):1783-8. doi: 10.1007/s11605-011-1624-5. Epub 2011 Jul 28.

42. Roviello F1, Rossi S, Marrelli D, Pedrazzani C, Corso G, Vindigni C, et al. Number of lymph node metastases and its prognostic significance in early gastric cancer: a multicenter Italian study. J Surg 
Oncol.2006 Sep 15;94(4):275-80; discussion 274.

43. Fukuhara S, Yabe M, Montgomery MM, Itagaki S, Brower ST, Karpeh MS Jr.

Race/Ethnicity is predictive of lymph node status in patients with early gastric cancer. $\mathrm{J}$ Gastrointest Surg.2014 Oct;18(10):1744-51.

\section{Tables}

\section{Table 1 Baseline characteristics and prognostic single- factors analysis in EGC patients. $(\mathrm{N}=120)$}




\begin{tabular}{|c|c|c|c|c|}
\hline Variable & Mean,SD/n & $\begin{array}{l}\text { 5-survival } \\
\text { rate }\end{array}$ & $x^{2}$ & $\begin{array}{l}\mathrm{P} / \mathrm{t} \\
\text { value }\end{array}$ \\
\hline Gender & & & 0.792 & 0.373 \\
\hline Male & $73(71.9 \%)$ & $91.3 \%$ & & \\
\hline Female & $47 /(28.1 \%)$ & $86.6 \%$ & & \\
\hline Age(years) & $54.74 \pm 11.68$ & $90 \%$ & 99.357 & 0.000 \\
\hline $\begin{array}{l}\text { Mean,SD※ } \\
\mathrm{Hb} \square \mathrm{g} / \mathrm{l} \square \mathbb{}\end{array}$ & $135.09 \pm 22.76$ & $90 \%$ & 197.586 & 0.000 \\
\hline $\begin{array}{l}\text { Mean,SD } \\
\text { Pre-albumin(mg/dl) }\end{array}$ & $280.34 \pm 67.36$ & $92 \%$ & 264.163 & 0.000 \\
\hline $\begin{array}{l}\text { Mean,SD } \\
\text { Ca-199(u/ml) }\end{array}$ & $11.94 \pm 16.38$ & $90.7 \%$ & 113.39 & 0.096 \\
\hline $\begin{array}{l}\text { Mean,SD } \\
\text { CEA(ng/ml) } \\
\text { Mean,SD }\end{array}$ & $1.78 \pm 1.72$ & $90 \%$ & 99.82 & 0.164 \\
\hline Tumor size(cm) & $2.81 \pm 2.11$ & $90 \%$ & 25.32 & 0.021 \\
\hline $\begin{array}{l}\text { Mean,SD } \\
\text { Tumor location }\end{array}$ & & & 0.387 & 0.824 \\
\hline Upper & $3(2.5 \%)$ & $100 \%$ & & \\
\hline Middle & $23(19.2 \%)$ & $91.3 \%$ & & \\
\hline Lower & $94(78.3 \%)$ & $88.5 \%$ & & \\
\hline Macroscopic type & & & 3.717 & 0.446 \\
\hline Elevated & $21(17.5 \%)$ & $95.2 \%$ & & \\
\hline Flat & $46(38.3 \%)$ & $83.8 \%$ & & \\
\hline Depressed & $40(33.3 \%)$ & $89.1 \%$ & & \\
\hline Mixed & $6(5 \%)$ & $100 \%$ & & \\
\hline $\mathrm{x}$ & 7 & & & \\
\hline Differentiation & & & 1.044 & 0.959 \\
\hline
\end{tabular}




\begin{tabular}{|c|c|c|c|c|}
\hline Well & $12(10 \%)$ & $83.3 \%$ & & \\
\hline moderate & $55(45.8 \%)$ & $92 \%$ & & \\
\hline poor & $44(36.7 \%)$ & $88.3 \%$ & & \\
\hline signet & $7(5.8 \%)$ & $85.7 \%$ & & \\
\hline mucinous & 1 & & & \\
\hline$x$ & 1 & & & \\
\hline Stage N+ & & & 36.008 & 0.000 \\
\hline NO & $101(84.2 \%)$ & $92.7 \%$ & & \\
\hline $\mathrm{N} 1$ & $10(8.3 \%)$ & $78.8 \%$ & & \\
\hline N2 & $8(6.7 \%)$ & $71.4 \%$ & & \\
\hline N3a & $1(0 \%)$ & & & \\
\hline Stage $T^{\star}$ & & & 0.041 & 0.84 \\
\hline T1a & $28(23.3 \%)$ & $92.6 \%$ & & \\
\hline $\mathrm{T} 1 \mathrm{~b}$ & $92(76.7 \%)$ & $88.5 \%$ & & \\
\hline
\end{tabular}

\footnotetext{
*T1a tumor has invaded mucosa layer; ;1 b tumor has invaded submucosa layer;+N0 no regional lymph node metastasis;N1 1-2 regional lymph node metastasis;N2 3-6 regional lymph node metastasis;and N3a 7-15 regional lymph node metastasis;N3b $\geq 15$ regional lymph node metastasis.

※SD standard deviation; $\square \mathrm{Hb}$ haemoglobin;;X unknow type.
}

\section{Table 2 Multivariate Cox stepwise proportional hazard model for overall survival in EGC.}




\begin{tabular}{|c|c|c|c|}
\hline Variables & $\mathrm{x} 2$ & $\bar{P}$ & hazard ratio $(95 \% \mathrm{CI})$ \\
\hline & 8.463 & 0.004 & $0.967 \square 0.945 \square 0.989 \square$ \\
\hline de metastasis & 17.280 & 0.000 & $3.650 \square 1.97$ \\
\hline
\end{tabular}

\section{Table 3 Clinicopathologic findings in patients with early} gastric carcinoma with and without lymph node metastasis 


\begin{tabular}{|c|c|c|c|}
\hline Variables & Node-negative & Node-positive & $\mathrm{P} / \mathrm{t}$ value \\
\hline Ago (voard & $\frac{n=109}{5587+1120}$ & $\mathrm{n}=19$ & 0011 \\
\hline (e) & & & \\
\hline $\begin{array}{l}\text { Mean,SD } \\
\text { sex }\end{array}$ & & & 0.451 \\
\hline Male & $63(62.4 \%)$ & $10(52.6 \%)$ & \\
\hline Female & $38(37.6 \%)$ & $9(47.4 \%)$ & \\
\hline $\mathrm{Hb} \square \mathrm{g} / \mathrm{I} \square$ & $133.5 \pm 23.61$ & $143.10 \pm 15.68$ & 0.095 \\
\hline $\begin{array}{l}\text { Mean,SD } \\
\text { Pre-albumin(mg/dl) }\end{array}$ & $279.8 \pm 66.91$ & $282.7 \pm 71.56$ & 0.864 \\
\hline $\begin{array}{l}\text { Mean,SD } \\
\text { CEA(ng/ml) Mean,SD } \\
\text { Ca-199(u/ml) }\end{array}$ & $\begin{array}{l}1.84 \pm 1.81 \\
10.63 \pm 11.74\end{array}$ & $\begin{array}{l}1.47 \pm 1.15 \\
18.90 \pm 30.78\end{array}$ & $\begin{array}{l}0.393 \\
0.043\end{array}$ \\
\hline $\begin{array}{l}\text { Mean,SD } \\
\text { Tumor size(cm) }\end{array}$ & $2.289 \pm 2.24$ & $2.39 \pm 1.17$ & 0.350 \\
\hline $\begin{array}{l}\text { Mean,SD } \\
\text { Tumor location }\end{array}$ & & & 0.671 \\
\hline Upper & $3(3 \%)$ & $0(0)$ & \\
\hline Middle & $20(19.8 \%)$ & $3(15.8 \%)$ & \\
\hline Lower & $78(77.2 \%)$ & $16(84.2 \%)$ & \\
\hline Macroscopic type & & & 0.136 \\
\hline Elevated & $16(15.8 \%)$ & $5(26.3 \%)$ & \\
\hline Flat & $37(36.6 \%)$ & $9(47.4 \%)$ & \\
\hline Depressed & $36(35.6 \%)$ & $4(21.1 \%)$ & \\
\hline Mixed & $5(5.0 \%)$ & $1(5.3 \%)$ & \\
\hline $\mathrm{x}$ & 0 & $1(5.3 \%)$ & \\
\hline
\end{tabular}

Differentiation 


\begin{tabular}{lll} 
Well & $12(11.9 \%)$ & 0 \\
moderate & $47(46.5 \%)$ & $8(42.1 \%)$ \\
poor & $34(33.7 \%)$ & $10(52.6 \%)$ \\
signet & $7(6.9 \% \square$ & 0 \\
mucinous & $101 \% \square$ & 0 \\
x & 0 & $105.3 \% \square$ \\
Stage T & & \\
T1a & $23(22.8 \%)$ & $5(26.3 \%)$ \\
T1b & $78(77.2 \%)$ & $14(73.7 \%)$ \\
\hline
\end{tabular}

Table 4 Multivariate logistic regression analysis for variables associated with lymph node metastasis in EGC.

\begin{tabular}{|c|c|c|c|c|}
\hline Variables & Risk ratio & $95 \% \mathrm{Cl}$ & $x 2$ & P value \\
\hline $\begin{array}{l}\text { Age } \\
\text { Ca-199 }\end{array}$ & $\begin{array}{l}0.910 \\
1.043\end{array}$ & $\begin{array}{l}0.867-0.956 \\
1.018-1.069\end{array}$ & $\begin{array}{l}14.418 \\
11.867\end{array}$ & $\begin{array}{l}0.000 \\
0.001\end{array}$ \\
\hline Macroscopic typ & 0.551 & $0.321-0.949$ & 4.622 & 0.032 \\
\hline
\end{tabular}

\section{Figures}




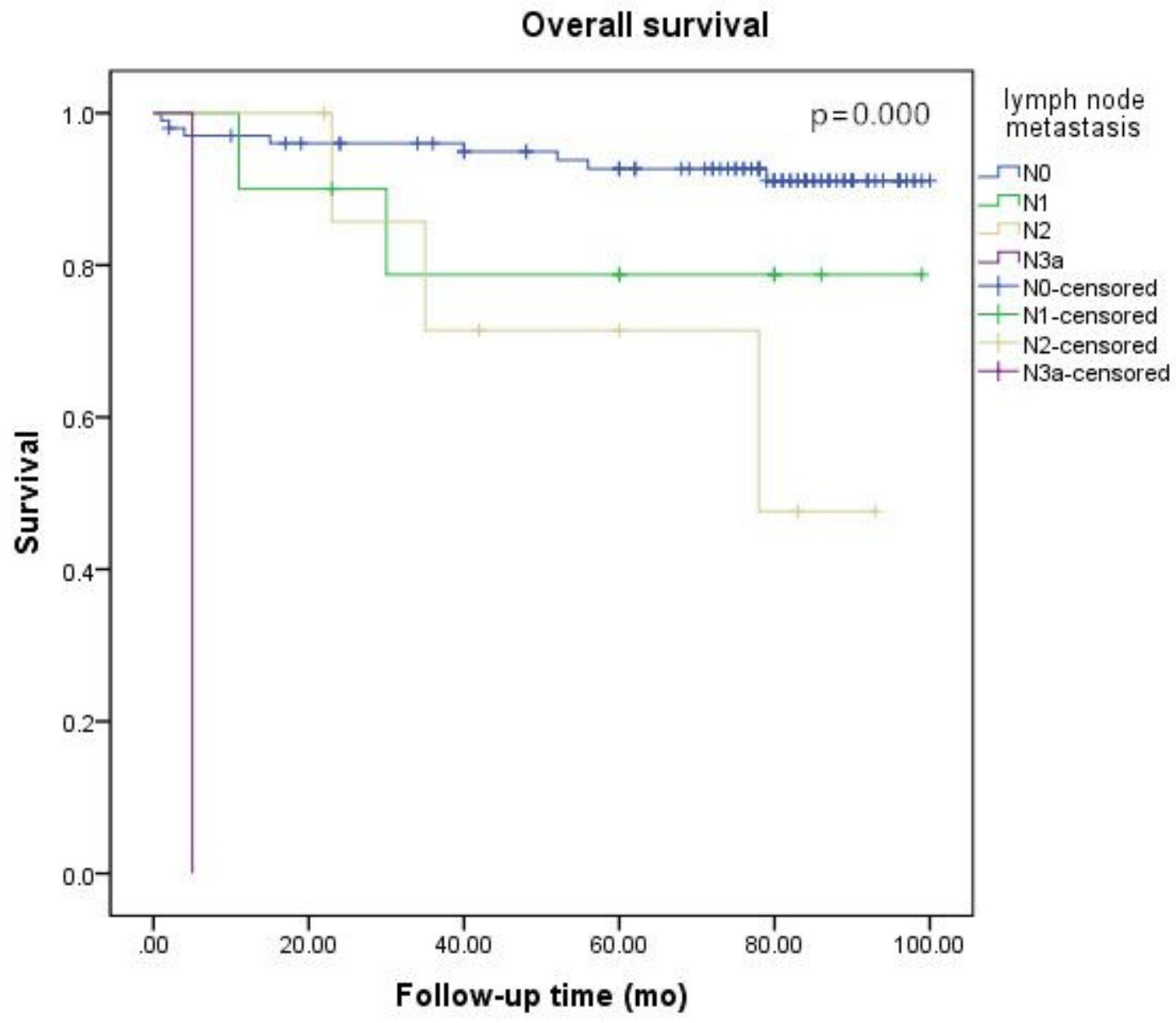

Figure 1

The Kaplan-Meier survival curve indicated that more LNMs were predictive of a worse prognosis compared with fewer LNMs in EGC. 